\title{
An evaluation of association of vitamin D insufficiency with gestational hypertension in pregnant women
}

\author{
Khan Arshiya, Srivastava Meenakshi*
}

\begin{abstract}
Department of Obstetrics and Gynecology, Integral Institute of Medical Sciences and Research, Lucknow, Uttar
\end{abstract} Pradesh, India

\author{
Received: 15 March 2018 \\ Revised: 03 June 2018 \\ Accepted: 05 June 2018

\section{*Correspondence:} \\ Dr. Srivastava Meenakshi, \\ E-mail: dreamdubai2017@gmail.com
}

Copyright: ( $)$ the author(s), publisher and licensee Medip Academy. This is an open-access article distributed under the terms of the Creative Commons Attribution Non-Commercial License, which permits unrestricted non-commercial use, distribution, and reproduction in any medium, provided the original work is properly cited.

\begin{abstract}
Background: Preeclampsia (PE) is a disease specific to pregnancy affecting many bodily systems. This is characterized by high blood pressure and proteinuria after the 20th week of pregnancy. The objective of this study was to evaluate of association of vitamin D insufficiency with gestational hypertension in pregnant women.

Methods: This was a cross-sectional study. A total of 104 pregnant women were included in the study. The diagnosis of gestational hypertension was confirmed using the "Report of the American College of Obstetricians and Gynaecologists' Task Force on Hypertension in Pregnancy" criteria. Based on these criteria, patients with systolic blood pressure $\geq 140 \mathrm{mmHg}$ and/or diastolic blood pressure $\geq 90 \mathrm{mmHg}$ (measured after a period of rest of four hours, twice daily) and proteinuria ( $\geq 300 \mathrm{mg}$ protein/24 h) were diagnosed as gestational hypertension.

Results: Vitamin D deficiency was found among 78.9\% (90/114) women. There was no significant $(p>0.05)$ difference in age of women between vitamin D deficient and sufficient. Vitamin D level was significantly ( $\mathrm{p}=$ $0.0001)$ lower among the women between Vitamin D deficient $(15.93 \pm 4.66)$ and sufficient $(35.70 \pm 3.25)$. There was no significant ( $\mathrm{p}>0.05$ ) association of Vitamin D level with parity, family history of hypertension, blood pressure, gestational age and fasting blood glucose. There was significant $(\mathrm{p}=0.0001)$ difference in BMI between Vitamin D deficient $(30.10 \pm 4.95)$ and sufficient $(24.04 \pm 2.75)$. Tobacco consumption was also associated with the level of Vitamin D. There was significant negative correlation between BMI and Vitamin D level $(r=-0.56, p=0.00011)$.

Conclusions: The present study demonstrates that vitamin D plays a role in the ethology and pathophysiology of gestational hypertension. Among the population having the risk of vitamin D deficiency, the risk of pregnancy induced hypertension may be decreased through vitamin D supplementation.
\end{abstract}

Keywords: Gestational hypertension, Insufficiency, Pregnant women

\section{INTRODUCTION}

Preeclampsia (PE) is a disease specific to pregnancy affecting many bodily systems. This is characterized by high blood pressure and proteinuria after the $20^{\text {th }}$ week of pregnancy. This complicates $2-8 \%$ of pregnancies. This increases maternal and fetal mortality and morbidity. Different factors such as angiogenetic, endothelial dysfunction, syncytiotrophoblastic microparticles and inflammatory activation play an important role in the progression of preeclampsia. ${ }^{1}$ The maternal diets are associated with the etiology of preeclampsia. $^{2}$

Vitamin D has received great attention as a possible etiological factor in pre-eclampsia. Vitamin D deficiency can affect the health of both mother and fetus by increasing the production of inflammatory cytokines and stimulating the activity of T-regulatory cells. It results in 
poor bone mineralization in infants, low birth weight and other adverse pregnancy outcomes. ${ }^{3}$

Epidemiological studies have shown the importance of vitamin $\mathrm{D}$ deficiency in the development of preeclampsia. ${ }^{4}$ The importance of vitamin D deficiency in immunomodulation and placental development has been highlighted in various studies. Thus, they put the emphasis on vitamin D deficiency regarding its probable role in the physiology of preeclampsia.,

The objective of the present study was to evaluate of association of vitamin D insufficiency with gestational hypertension in pregnant women.

\section{METHODS}

This was a cross-sectional study conducted in the Department of Obstetrics and Gynecology, Integral Institute of Medical Sciences, Lucknow. The study was approved by the Ethical Committee of the Institute. The consent was taken from each participant before including in the study.

A total of 104 pregnant women were included in the study. The diagnosis of gestational hypertension was confirmed using the Report of the American College of Obstetricians and Gynecologists criteria. Based on these criteria. Patients with systolic blood pressure $\geq 140$ $\mathrm{mmHg}$ and/or diastolic blood pressure $\geq 90 \mathrm{mmHg}$ and proteinuria $\geq 300 \mathrm{mg}$ protein $/ 24 \mathrm{~h}$ ) were diagnosed as gestational hypertension.?

The acceptance criteria for gestational hypertensive women for the study was if they had normal blood pressure during the first 20 weeks of gestation, no previous history of metabolic disorders, twin pregnancy, recurrent miscarriage, fetal growth retardation, placenta abruption, thrombophilia, renal disease, chronic hypertension or diabetes mellitus as well as no history of antioxidant intake and no medication for hypertension.

The interval between the first day of the mother's last menstrual period and expected date of delivery was defined as gestational age.

None of the patients were on any medication at the time of blood sample collection. Demographic and clinical data were collected during routine obstetric visits. Fasting venous blood specimen was taken from the antecubital vein and collected in vacutainers with no additives. The serum separator tube specimens were allowed to clot. Then centrifuged for 10 minutes at 3,000 g to separate the serum and stored at $-70^{\circ} \mathrm{C}$ until analyzed.

Total vitamin D assays were analyzed with the fully automatic Advia Centaur XP immunoassay systems. Results were automatically calculated to the standard deviation.
The SPSS 16.0 version (Chicago, Inc., USA) was used to analyze the data. Normal distribution was tested using the Shapiro-Wilk test and variability coefficients. The data with normal distribution was analyzed using parametric methods. Two independent groups were compared using the Student unpaired t-test. Categorical variables were compared using the Pearson Chi-Square test. Quantitative data was expressed as a mean \pm SD (standard deviation). Categorical values were expressed as numbers (n) and percentages $(\%)$. A p-value $<0.05$ was considered significant.

\section{RESULTS}

Vitamin D deficiency was found among $78.9 \%$ (90/114) women (Figure 1).

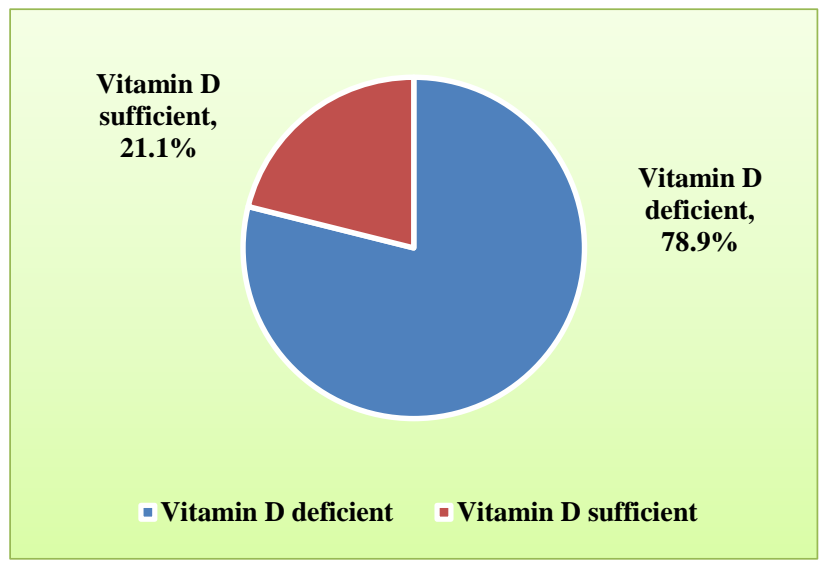

Figure 1: Distribution of Vitamin D deficiency.

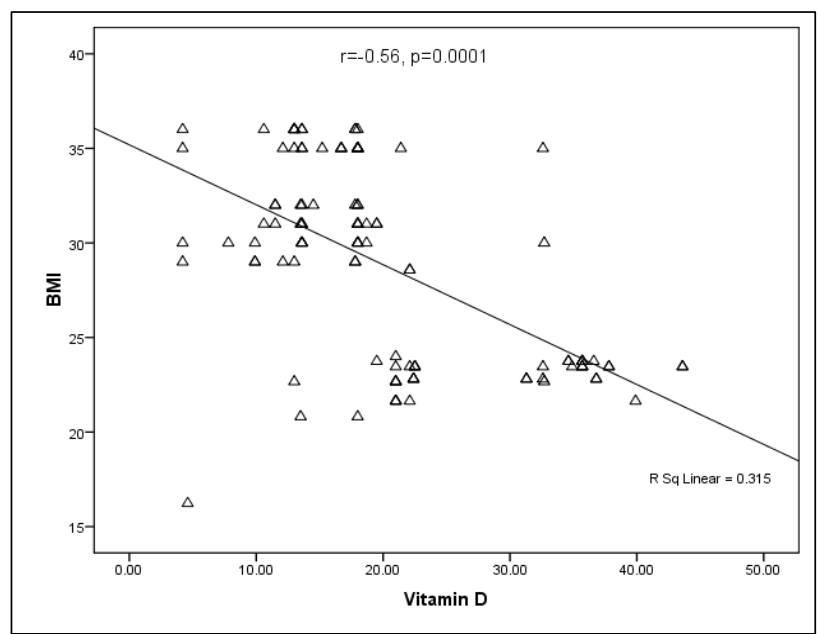

Figure 2: Correlation between Vitamin D and BMI.

There was no significant $(\mathrm{p}>0.05)$ difference in age of women between vitamin $\mathrm{D}$ deficient and sufficient. Vitamin D level was significantly $(p=0.0001)$ lower among the women between Vitamin $\mathrm{D}$ deficient $(15.93 \pm 4.66)$ and sufficient $(35.70 \pm 3.25)$. There was no significant $(\mathrm{p}>0.05)$ association of Vitamin D level with parity, family history of hypertension, blood pressure, 
gestational age and fasting blood glucose. There was significant $(\mathrm{p}=0.0001)$ difference in BMI between Vitamin D deficient $(30.10 \pm 4.95)$ and sufficient (24.04 \pm 2.75$)$. Tobacco consumption was also associated with the level of Vitamin D (Table 1).

Table 1: Comparison of Vitamin D status with basic characteristics of women.

\begin{tabular}{|c|c|c|c|}
\hline \multirow{2}{*}{$\begin{array}{l}\text { Basic } \\
\text { characteristics }\end{array}$} & \multicolumn{2}{|c|}{ Vitamin D status (ng/dl) } & \multirow[t]{2}{*}{ p-value } \\
\hline & $\begin{array}{l}\leq 30 \\
(n=90)\end{array}$ & $\begin{array}{l}>30 \\
(n=24)\end{array}$ & \\
\hline $\begin{array}{l}\text { Age in years, } \\
\text { mean } \pm S D\end{array}$ & $26.83 \pm 6.49$ & $25.79 \pm 6.50$ & 0.48 \\
\hline Vitamin D level & $15.93 \pm 4.66$ & $35.70 \pm 3.25$ & $0.0001 *$ \\
\hline \multicolumn{4}{|l|}{ Parity, no. (\%) } \\
\hline Nullipara & $51(56.7)$ & $15(62.5)$ & \multirow{2}{*}{0.60} \\
\hline Multipara & $39(43.3)$ & $9(37.5)$ & \\
\hline \multicolumn{4}{|c|}{ Family history of hypertension, no. (\%) } \\
\hline Present & $19(21.1)$ & $2(8.3)$ & \multirow{2}{*}{0.12} \\
\hline Absent & $71(78.9)$ & $22(91.7)$ & \\
\hline \multicolumn{4}{|l|}{ Tobacco habit } \\
\hline Present & $71(78.9)$ & $9(37.5)$ & \multirow{2}{*}{$0.0001 *$} \\
\hline Absent & $19(21.1)$ & $15(62.5)$ & \\
\hline $\begin{array}{l}\mathrm{BMI}, \\
\text { mean } \pm \mathrm{SD}\end{array}$ & $30.10 \pm 4.95$ & $24.04 \pm 2.75$ & $0.0001 *$ \\
\hline $\begin{array}{l}\text { Systolic blood } \\
\text { pressure, } \\
\text { mean } \pm \text { SD }\end{array}$ & $121.50 \pm 11.04$ & $117.17 \pm 9.56$ & 0.06 \\
\hline $\begin{array}{l}\text { Diastolic blood } \\
\text { pressure } \\
\text { mean } \pm \text { SD }\end{array}$ & $72.51 \pm 11.55$ & $68.25 \pm 9.55$ & 0.10 \\
\hline $\begin{array}{l}\text { Gestational age } \\
\text { in weeks, } \\
\text { mean } \pm \text { SD }\end{array}$ & $26.43 \pm 1.48$ & $25.71 \pm 1.48$ & 0.06 \\
\hline $\begin{array}{l}\text { Fasting blood } \\
\text { glucose } \\
\text { mean } \pm \text { SD }\end{array}$ & $157.54 \pm 7.62$ & $155.25 \pm 11.14$ & 0.24 \\
\hline
\end{tabular}

There was significant negative correlation between BMI and Vitamin D level $(r=-0.56, p=0.00011)$ (Figure 2).

\section{DISCUSSION}

Pathogenesis of gestational hypertension is complex, and a vitamin $\mathrm{D}$ deficiency is one of the factors in the etiology of gestational hypertension. Vitamin D is being considered a major role in the synthesis and regulation of genes. They are effective in the development of placenta. ${ }^{8}$ Deep trophoblast invasion and remodeling of the vascular structures in the placental bed play a role in the development of gestational hypertension. ${ }^{9}$ Vitamin D deficiency has been advocated to be a predisposing factor for the peripheral vascular phase modulation. This results in inadequate placental development and the development of gestational hypertension. ${ }^{10}$

It has been reported that the production of vitamin D in the decidua placenta and the maternal kidneys increases during pregnancy. ${ }^{11}$ Because, vitamin $\mathrm{D}$ level is being dependent on the sunlight exposure and dietary factors, there may be little or no change in the level of vitamin D during pregnancy. ${ }^{12}$

In the present study, Vitamin D deficiency was found among $78.9 \%$ women. The studies conducted in USA, Australia, the Middle East and South Asia, vitamin D deficiency was found to be in $26-98 \%$ of pregnant women. Vitamin D deficiency has been reported to be 66$100 \%$ among the women with a dark skin color. ${ }^{13,14}$

In this study, there was significant $(\mathrm{p}=0.0001)$ difference in BMI between Vitamin D deficient $(30.10 \pm 4.95)$ and sufficient (24.04 \pm 2.75$)$. Similar finding was reported in the study by Bakacak et al. ${ }^{2}$

Based on the literature, establishing the relationship between gestational hypertension and vitamin $\mathrm{D}$ is complicated. There are various studies on the role of vitamin $\mathrm{D}$ on the development and pathophysiology of gestational hypertension. A low vitamin D level in the second trimester has been emphasized in previous studies to be an indicator of gestational hypertension. ${ }^{15,16}$

In the present study, there was significant $(p=0.0001)$ difference in BMI between Vitamin D deficient

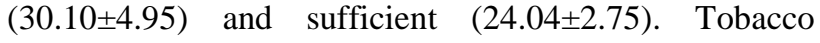
consumption was also associated with the level of Vitamin D. Bakacak et al reported similar findings. ${ }^{2}$

The studies on the role of vitamin D in the development of gestational hypertension and vitamin $\mathrm{D}$ have been emphasized to play an immunomodulatory and antiinflammatory role in many systems. ${ }^{17}$ Vitamin D has been suggested to play an important role in signal and gene regulations in the development of placental trophoblasts in the placental growth. ${ }^{18,8}$

\section{CONCLUSION}

The present study demonstrates that vitamin $\mathrm{D}$ plays a role in the etiology and pathophysiology of gestational hypertension. Among the population having the risk of vitamin D deficiency, the risk of pregnancy induced hypertension may be decreased through vitamin D supplementation.

\section{Funding: No funding sources \\ Conflict of interest: None declared}

Ethical approval: The study was approved by the Institutional Ethics Committee

\section{REFERENCES}

1. Roberts JM, Hubel CA. The two-stage model of preeclampsia: variations on the theme. Placenta. 2009;30:S32-7.

2. Bakacak M, Serin S, Ercan O. Comparison of Vitamin D levels in cases with preeclampsia, 
eclampsia and healthy pregnant women. Int J Clin Exp Med. 2015;8(9):16280-6.

3. Tabesh M, Salehi-Abargouei A, Tabesh M, Esmaillzadeh A. Maternal Vitamin D status and risk of pre-eclampsia: a systematic review and metaanalysis. J Clin Endocrinol Metabol. 2013;98(8):3165-73.

4. Wei S, Audibert F, Hidiroglou N, Sarafin K, Julien $\mathrm{P}, \mathrm{Wu} \mathrm{Y}$, et al. Longitudinal vitamin $\mathrm{D}$ status in pregnancy and the risk of pre-eclampsia. BJOG. 2012;119:832-9.

5. Fischer D, Schroer A, Ludders D, Cordes T, Bücker B, Reichrath J, et al. Metabolism of vitamin D3 in the placental tissue of normal and preeclampsia complicated pregnancies and premature births. Clin Exp Obstet Gynecol. 2007;34:80-4.

6. Diaz L, Noyola-Martinez N, Barrera D, Hernández G, Avila E, Halhali A, et al. Calcitriol inhibits TNFalpha-induced inflammatory cytokines in human trophoblasts. J Reprod Immunol. 2009;81:17-24.

7. Snydal S. Major changes in diagnosis and management of preeclampsia. J Midwifery Women's Health. 2014;59:596-605.

8. Novakovic B, Sibson M, Ng HK, Manuelpillai U, Rakyan V, Down T, et al. Placenta-specific methylation of the vitamin D 24-hydroxylase gene: implications for feedback autoregulation of active vitamin D levels at the fetomaternal interface. J Biol Chem. 2009;284:14838-48.

9. Huppertz B. Placental origins of preeclampsia challenging the current hypothesis. Hypertension. 2008;51:970-5.

10. Ullah MI, Koch CA, Tamanna S, Rouf S, Shamsuddin L. Vitamin D deficiency and the risk of preeclampsia and eclampsia in Bangladesh. Horm Metab Res. 2013;45:682-7.

11. Pérez-López FR. Vitamin D: the secosteroid hormone and human reproduction. Gynecol Endocrinol. 2007;23:13-24.
12. Fernández-Alonso AM, Dionis-Sánchez EC, Chedraui P, González-Salmerón MD, Pérez-López FR, Spanish Vitamin D and Women's Health Research Group. First-trimester maternal serum 25hydroxyvitamin D3 status and pregnancy outcome. Int J Gynaecol Obstet. 2012;116:6-9.

13. Johnson DD, Wagner CL, Hulsey TC, McNeil RB, Ebeling M, Hollis BW. Vitamin D deficiency and insufficiency is common during pregnancy. Am J Perinatol. 2011;28:7-12.

14. Teale GR, Cunningham CE. Vitamin D deficiency is common among pregnant women in rural Victoria. Aust N Z J Obstet Gynaecol. 2010;50:259-61.

15. Bodnar LM, Catov JM, Simhan HN, Holick MF, Powers RW, Roberts JM. Maternal vitamin D deficiency increases the risk of preeclampsia. J Clin Endocrinol Metab. 2007;92:3517-22.

16. Haugen M, Brantsaeter AL, Trogstad L, Alexander J, Roth C, Magnus P, et al. Vitamin D supplementation and reduced risk of preeclampsia in nulliparous women. Epidemiol. 2009;20:720-6.

17. Xu L, Lee M, Jeyabalan A, Roberts JM. The relationship of hypovitaminosis D and IL-6 in preeclampsia. Am J Obstet Gynecol. 2014;210:149.

18. Fischer D, Schroer A, Ludders D, Cordes T, Bücker B, Reichrath J, et al. Metabolism of vitamin D3 in the placental tissue of normal and preeclampsia complicated pregnancies and premature births. Clin Exp Obstet Gynecol. 2007;34:80-4.

Cite this article as: Arshiya K, Meenakshi S. An evaluation of association of vitamin D insufficiency with gestational hypertension in pregnant women. Int J Reprod Contracept Obstet Gynecol 2018;7:310912. 